\title{
A CONCEPÇÃO DE RACIONALIDADE E JUSTIÇA EM ALASDAIR MACINTYRE
}

\author{
THE CONCEPTION OF RATIONALITY AND JUSTICE IN ALASDAIR MACINTYRE
}

Giovani Orso Borile

Mestre em Direito Ambiental

Universidade de Caxias do Sul - Rio Grande do Sul - RS / Brasil

goborile@ucs.br

Cleide Calgaro

Pós-Doutora em Filosofia e em Direito

Universidade de Caxias do Sul - Rio Grande do Sul - RS / Brasil

ccalgaro1@hotmail.com

(iD Gina Chávez Vallejo

Doctora en Derecho

Centro de Derechos y Justicia del Instituto de Altos Estudios Nacionales, IAEN

gina.chavez@iaen.edu.ec

Resumo: O presente trabalho analisa o conceito e campo da racionalidade e da justiça no âmbito da teoria de Alasdair Macintyre, passando por um estudo acerca da ideia de razão e racionalidade e da perspectiva de equidade, para então compreender a proposta de justiça e racionalidade do autor. Busca-se elaborar um diagnóstico sobre o processo de justiça e da expectativa de equidade para, por fim, demonstrar a necessidade de implantação de um estudo acerca do agir justo, juntamente com o desenvolvimento de uma consciência racional por meio do acesso aos recursos referentes ao processo de justiça. O método empregado no presente trabalho é o hermenêutico. Conclui-se que a justiça é constituída por um processo de racionalidade iniciado dentro do indivíduo e finalizado através do bem realizado ou agir justo.

Palavras-chave: Racionalidade. Justiça. Alasdair Macintyre.

Abstract: The present work analyze the concept and field of rationality and justice within the framework of Alasdair Macintyre 's theory, going through a brief study about the idea of reason and rationality and the perspective of equity, in order to understand the proposal of justice and rationality in Alasdair MacIntyre. It seeks to elaborate a diagnosis about the process of justice and the expectation of equity, in order to demonstrate the need to implement a study on fairness, together with the development of a rational conscience through access to resources related to process of justice. The method employed in the present work is the hermeneutic. It concludes that justice consists of a process initiated within the individual and finalized through realized good or just action.

Keywords: Rationality. Justice. Alasdair Macintyre

\section{Para citar este artigo}

\section{ABNT NBR 6023:2018}

BORILE, Giovani Orso; CALGARO, Cleide; VALLEJO, Gina. Chávez. A concepção de racionalidade e justiça em Alasdair Macintyre. Prisma Jurídico, São Paulo, v. 19, n. 2, p. 210-224, jul./dez. 2020.

http://doi.org/10.5585/prismaj.v19n2.16991. 


\section{Considerações iniciais}

A vida cotidiana e os mais variados problemas éticos da sociedade moderna possibilitam ao indivíduo o surgimento de inúmeros questionamentos referentes aos contextos de justiça, as razões ou boas razões que levarão o indivíduo a ação constitui-se em fase anterior ao processo reflexivo e possibilita ao indivíduo que seja conduzido pelas mais variadas intuições.

As motivações e os impulsos aparecem e possibilitam a reflexão, de modo que no presente estudo faz-se uma análise acerca dos procedimentos de reflexão, consistindo, na verdade, no elemento propulsor que condiciona o pensamento e inspira o procedimento reflexivo na construção do raciocínio prático.

O processo de raciocínio é movido basicamente pelas potencialidades norteadoras que emergem no processo reflexivo e que promoverá o bom e o melhor não somente para a comunidade em que estará inserido o indivíduo, mas para ele próprio.

As razões para a ação do indivíduo que influenciam o julgamento das condutas e fomentam o progresso da justiça nesse sistema de raciocínio permite-nos entender como funciona na teoria e prática as questões de mérito, merecimento e justiça.

O método utilizado para o presente estudo é o hermenêutico visto que, pretende-se compreender as perspectivas de justiça e racionalidade a partir da interpretação de percepções teóricas do autor, onde pela pesquisa bibliográfica infere-se a ideia de justiça oriunda do processo racional intelectivo.

$\mathrm{Na}$ primeira seção, realiza-se a análise da vida e obra de Alasdair MacIntyre, posteriormente, faz-se num segundo momento a indagação acerca da teoria do autor e sua utilização na aplicação do raciocínio prático, analisando questões como Justiça e Racionalidade e a justiça como processo e procedimento rumo a uma equidade, buscando por fim na terceira seção o entendimento acerca do bem-estar na polis como corolário do processo de justiça.

\section{A vida e obra de Alasdair Macintyre}

Alasdair MacIntyre nasceu em Glasgow na Escócia, tendo estudado no Queen Mary College, na Universidade de Londres e na Universidade de Manchester, ao mudar-se para os EUA seguiu uma considerável carreira universitária lecionando Filosofia em universidades como a de Boston, Notre Dame, Vanderbilt e Duke. (PERREAU-SAUSSINE, 2005. p.6).

Pode-se salientar que a teoria de Alasdair MacIntyre é justificada pelo fato de não identificar-se com as surgidas com o moderno iluminismo. Uma das principais preocupações da teoria de MacIntyre é o estudo acerca da razão, racionalidade e justiça. Tecendo, outrossim, 
uma crítica à fragilidade da ética moderna bem como criticando a perspectiva individualista liberal, idealizando certo comunitarismo ético.

Entretanto a complexidade da teoria de MacIntyre é de laboriosa caracterização, mais especialmente pela questão de que a perspectiva histórica é a ferramenta mais adequada, segundo o autor, para identificar as ideias, correntes e tradições.

De fato, o que Alasdair MacIntyre procura ao delimitar o contexto histórico é sem dúvidas demonstrar que não é possível o entendimento do critério moral e ainda a compreensão de parâmetros e conceitos éticos sem a devida referência ao período histórico que os originou, não é possível um parâmetro ético sem o estudo do conteúdo histórico da ética.

Alasdair MacIntyre é um dos principais representantes e um dos mais importantes contribuintes da atual ética e filosofia política. Idealizando a perspectiva aristotélica e permitindo uma complexa construção teórica acerca dos temas políticos e morais atuais. Ao introduzir lições acerca da obra de Homero e questões da Grécia antiga instrui acerca de temas como justiça, equidade, ética, bem como leciona que o homem é um ser político por natureza e que a vida em sociedade é fundamental para o aperfeiçoamento das suas virtudes.

MacIntyre busca na interpretação de outros teóricos entender o sentido da interpretação fora da realidade social, do conteúdo social e da tradição de onde vieram, ressaltando sua importância da perspectiva histórica e desqualificando as ideias contrárias ao seu pensamento. (MURPHY, 2003. p. 5).

Segundo MacIntyre é impossível compreender a moral desligando-se as questões morais de seus contextos e das circunstâncias, sem perder de vista o caráter historicista, situado e contextual da ética.

No início, em suas primeiras obras, MacIntyre resume a ética moderna e contemporânea desde o Renascimento até o século XX, sendo possível perceber que o que mais afasta a ética de MacIntyre da ética moderna é a concepção kantiana do imperativo categórico. (CAMPELO, 2014. p.4). De modo que Kant defende que o homem deve agir no respeito por máximas como se fossem leis universais. (WILLASCHEK, 2002). Para MacIntyre, no entanto, na vida real, não existe tal coisa. O homem como agente moral é um ser situado, condicionado pelas circunstâncias e com laços que o prendem a uma comunidade com uma dada tradição. (CAMPELO, 2014. p.4). Pretender que é possível criar abstratamente um homem universal, capaz de se libertar das circunstâncias e separado da comunidade e da tradição, é o mesmo que recusar a evidência da evolução histórica e da diversidade cultural. (CAMPELO, 2014. p.4). 
Campelo ainda ressalta que ao analisar a História Ocidental percebe-se que a ética ocidental mudou os contextos históricos e culturais. E analisando a história, pode-se perceber, ainda,

\begin{abstract}
que a ética de cada sociedade está condicionada aos seus aspectos históricos. A ética da Grécia arcaica, por exemplo, não é a mesma da ética da Grécia clássica. Basta comparar a tábua de virtudes de Homero e de Hesíodo com a tábua de virtudes de Platão e Aristóteles, para se perceber as diferenças. Assim como também a ética da Grécia clássica se distingue da ética da cristã da Alta Idade Média e esta da ética do Renascimento, aí por diante. Portanto, o reconhecimento deste historicismo constitui a grande contribuição de MacIntyre para a ética contemporânea. Quando o livro "Depois da Virtude" foi publicado, em 1981, foi imediatamente reconhecido como uma das maiores críticas à filosofia moral contemporânea. O cerne do livro ocupa-se da relação da filosofia com a história e da questão do relativismo das virtudes. No livro, MacIntyre aborda questões sobre a natureza do desacordo moral atual, o projeto iluminista da justificação da moral, razões que explicam o fracasso do projeto iluminista, as virtudes nas sociedades heróicas, as virtudes em Aristóteles, as virtudes na Idade Média, a concepção tradicional das virtudes e, ainda, a ética Nietzsche face à ética de Aristóteles. (CAMPELO, 2014. p. 5).
\end{abstract}

Outrossim, neste momento percebe-se que MacIntyre faz a defesa filosófica da variedade e heterogeneidade das crenças, conceitos e práticas morais, revelando e explicando a ascensão e a queda das diferentes moralidades. Essa proposta leva MacIntyre ao pretexto da atual ausência de critérios morais que possam imprimir uma direção moral nas modernas sociedades ocidentais. (CAMPELO, 2014. p. 6). Na ausência de critérios morais, torna-se difícil arranjar argumentos para combater os novos males contemporâneos. Este fato resulta do afastamento total com as tradições, imposto por grande parte das concepções éticas póskantianas e pós-nietzscheanas. Assim, a concepção ética de MacIntyre é um dos exemplos de uma ética ancorada nos laços comunitários e culturais, onde o fato de ele ter fundamentado a sua ética em dois autores ignorados e combatidos pela ética individualista do iluminismo, respectivamente Aristóteles e Tomás de Aquino, torna a sua ética um caso ainda mais singular no panorama atual do pensamento filosófico. (CAMPELO, 2014. p. 6).

Desse modo, a ética de MacIntyre é uma ética teleológica, profundamente preocupada com a vida boa e com o bem. Mas é, também, uma ética racionalista e que não se distancia do processo de criação das emoções e dos afetos e da dependência das circunstâncias e dos contextos culturais e sociais, tornando-se uma ética situada. (CAMPELO, 2014. p. 6). Sobre o papel da razão, 


\begin{abstract}
MacIntyre afirma que a razão ensina tanto a encontrar o nosso verdadeiro objetivo como a alcançá-lo. Temos, então, um esquema tripartido no qual a natureza humana em estado natural é inicialmente discrepante e discordante dos preceitos da ética e precisa ser transformada pelo ensino e experiência da razão prática em natureza humana como ela deverá ser para poder realizar a sua finalidade. Cada um dos três elementos do esquema - a concepção da natureza em estado natural, a concepção dos preceitos da ética racional e a concepção da natureza como ela deverá ser para poder realizar a sua finalidade - requer referência aos outros dois estados para que o seu estado e a sua função se tornem inteligíveis. (CAMPELO, 2014. p. 6).
\end{abstract}

Portanto, a partir dessa ideia de razão é que vamos estudar a perspectiva de racionalidade e de agir justo, adentrando ao ramo da justiça e estabelecendo uma nova construção do ato justo a partir da lógica do racional.

\title{
2 Justiça e racionalidade: a justiça como processo e procedimento: rumo à equidade?
}

A dinâmica da justiça e o agir justo constituem questões merecedoras de um melhor esclarecimento, as discussões e os desencontros referentes à compreensão da justiça e da racionalidade prática foram essenciais para a abertura de novas proposições acerca da matéria. (CARDOSO, 2010. p. 100).

A participação na sociedade e a vida que nela se desenvolve constituem o ambiente propício ao desenvolvimento do agir justo e da justiça. (CARVALHO, 1999. p.21). A justiça de cada um e o agir justo possibilitam de forma simples e comum a equidade social.

A formação pessoal, a profissão e o meio em que o indivíduo está inserido viabilizam a concretização no campo da justiça de um ambiente de igualdade, de modo que o papel da filosofia acadêmica é compreender a partir do contexto social comum de que forma a justiça do indivíduo se perpetua como processo. (GONÇALVES, 2007. p. 18).

Esse processo inicia-se com o indivíduo, passa pelas interações diretas das relações, seu ápice ocorre na comunidade onde todas as relações sociais se encontram e se entrelaçam. A racionalidade emitida através de uma dialética interna no processo de justiça, e o exercício de uma argumentação tanto pessoal quanto construída permite o estabelecimento da equidade como parâmetro do justo.

A necessidade de se chegar a um consenso do que se trata a justiça comum ou a justiça de cada indivíduo instala um problema fundamental da racionalidade. (CARVALHO, 2004.p. 234). Como se apresenta o procedimento reflexivo? De que maneira o homem desenvolve o processo de ponderação? O que influencia cada um?

Questionamentos como estes surgem à medida em que se depara com a imprescindibilidade de discussão do que seja o agir justo. $\mathrm{O}$ âmago da discussão encontra-se na perspectiva de socialização da compreensão de que se deve providenciar o quanto antes o 
entendimento do que consiste a justiça e a razão e como se conectam num esquema de racionalidade e agir justo em ampla percepção. A evolução da justiça teve ampla ligação com a ideia de conflito. Conflitos sociais (ÁLVAREZ, 2017) ou até mesmo conflitos internos. Toda vez que desejamos partir para o justo ou requerer algo que nos foi injustamente tomado entramos em conflito.

Quando o requerem de se adentram ao conflito interno. Conceder ou não? Permitir ou não? Devolver ou não? Fazer ou não fazer? Inúmeros são os questionamentos. Entretanto quando se é que requerer a prestação de justiça essa percepção é visivelmente diferenciada.

Não há dúvidas, tudo é patente e ostensível, a discussão não ocorre tão profundamente no indivíduo como o é no caso de ser destinatário de requerimentos de justiça. O que se pretende é ampliar as discussões no que tange ao processo interno de justiça. O que é fazer a coisa certa? Esse questionamento será revisitado sob o ponto de vista do desenvolvimento interno, partindo de dentro do indivíduo e desabrochando no exercício da justiça.

A partir dessa ideia de processo interno e de justiça como procedimento iniciamos nossa análise acerca da dialética da equidade. A percepção de uma dimensão psicológica da justiça é fundamental (FERREIRA NETO, 2009) para alcançarmos a compreensão adequada acerca do tema, a questão dos desejos e as emoções funcionam muito bem como propulsores ou impedimentos ao exercício do agir justo. (MACINTYRE, 1990. p. 15).

A cultura também desempenha um papel fundamental na composição da justiça, dado que a questão dos valores e das virtudes varia de cultura para cultura e assim possibilita a partir da organização e articulação do mundo social público as nuances da justiça. Esse processo permeia as ideias de autocompreensão e de diálogo interno, um dito mundo interior, recheado de sentimentos, impulsos e motivações que conduzem o ente pela atividade da justiça.

O processo de decisão envolto em uma dimensão psicológica viabiliza o empreendimento do raciocínio e impulsiona a elaboração da reflexão sobre ele, esse esquema é que dá início ao processo de confecção da justiça. (COITINHO, 2017).

$\mathrm{O}$ procedimento de escolha e a tomada de decisões consistem em um processo individual. (DOLOVICH; NATAPOFF, 2017). Esse exercício, que figura como predecessor ou precursor do ato de justiça permite a reflexão acerca da atitude a ser tomada através da subordinação a um indivíduo. (GARGARELLA, 2008).

O modo como age o indivíduo é informado pela sua consciência, contudo antes mesmo do processo de ponderação há influência do meio (ERDI; ŞENTÜRK, 2017) e das virtudes, 
algo que não é somente nato, mas pode ser adquirido e ensinado a alguém, não se trata de ilusão, mas sim de processo. (BUTING, 2017).

A virtude surge como essência materializada pelas ações, sem dúvidas, a justiça é a principal das virtudes, necessitando consubstanciar todas as demais virtudes para corporalizar o ato justo. Segundo MacIntyre, o processo de decisão

tem de ser o que é essencialmente porque a justiça é o que é. A caracterização da ação e dos preâmbulos para ação torna imprescindível a referência à ordem cósmica de díke. A ordem cósmica pode ser transgredida, mas as consequências da transgressão são sinais da própria ordem. [...] O que quer que o termo 'justiça' nomeie, é certo que nomeia uma virtude; e, independentemente do mais que o bom raciocínio prático possa exigir, É certo que requer certas virtudes daqueles que o exibem. Esta história consequente será então necessariamente uma história da relação entre, por um lado, o raciocínio prático e a justiça e, por outro lado, as virtudes e, num plano mais geral, as concepções do que é o bem humano. $\mathrm{O}$ fato de que [...] a elucidação tanto de díke como da natureza da reflexão sobre ação prospectiva tem exigido também a discussão de areté e de ágathos acaba por nos mostrar que ela era necessária não apenas por si só, mas também como um momento preliminar à história posterior. (MACINTYRE, 1991. p. 34-5).

O papel do raciocínio prático é evidenciado basicamente no ato de ponderar, sopesando e cogitando ações, reações, resultados, vínculos, prejuízos ou benefícios. Esse exercício possibilita a concretude da atividade da justiça, a possibilidade de implementação da equidade como paradigma da sociedade, categorias como o virtuoso ou o bom são imprescindíveis para o estudo da justiça. Dessa forma:

[...] todo raciocínio prático desponta quando alguém pergunta: "Que devo fazer?" formular esta questão só faz sentido se alguma razão se apresentou ou foi apresentada ao agente para que faça algo diferente daquilo que faria em seguida, no curso normal das coisas. Boas razões para a ação, quando são eficientes para guiar a ação, são causas, uma causa é sempre algo que modifica um resultado. No caso da ação humana, a maior parte do tempo e na maioria das circunstâncias, os processos e procedimentos que as boas (ou más) razões para ação impingem causalmente são processos e procedimentos do dia normal, com seu programa de atividades rotineiras e cessação da atividade. Esta concepção do dia normal, do mês normal, do ano normal e assim por diante é da maior importância para se entender ação e o raciocínio sobre ação, em qualquer cultura. A estrutura da normalidade provê a sua estrutura mais básica para a compreensão da ação. [...] E uma boa razão para ação é, portanto, em primeira instância, uma razão suficientemente boa para fazer algo diferente daquilo que a normalidade prescreve. [...] E, assim, um raciocínio que justifica exigências particulares dessa estrutura pode emergir a partir do raciocínio que questiona. (MACINTYRE, 1991. p. 36-7).

A deliberação interna produz no indivíduo uma série de questionamentos do tipo: Como devo proceder? Quais as consequências? Que bem quero promover? A construção dessa concepção deve em todas as vias materializar-se em cada situação apresentada no cotidiano do indivíduo. (MACINTYRE, 2001). 
As razões funcionam como bons norteadores do agir justo, motivando não as ações diretamente, mas sim os pensamentos e desejos prospectivos. (CARVALHO, 2007, p. 17). O cotidiano e a dimensão da normalidade é que servem de ambiente propício ao desenvolvimento da justiça como virtude social ou do indivíduo, o dia-a-dia e o desenrolar da rotina de cada um é o melhor local para o desempenho dessa virtude. A vida cotidiana possibilita ao indivíduo o surgimento dos mais variados contextos de justiça, as razões ou boas razões para a ação são fases anteriores ao processo reflexivo e permitem ao cidadão que seja conduzido pelas mais variadas motivações.

Motivações ou impulsos surgem muito antes da reflexão, sendo na verdade o elemento propulsor que condiciona o pensamento e inspira o procedimento reflexivo na construção do raciocínio prático. O processo de raciocínio prático é justificado basicamente pelas questões que emergem no processo racional que promoverá o bom e o melhor não somente para a comunidade em que estará inserido o indivíduo, mas para ele próprio.

As ditas boas razões para a ação que influenciam o julgamento das condutas do homem fomentam de forma substancial o progresso da justiça, esse sistema de educação do raciocínio para o exercício do justo permite-nos entender como funciona na teoria e prática as questões de mérito, merecimento e justiça.

Dessa forma, as razões para a ação

\begin{abstract}
que eu e os outros configuramos boas - e cuja atribuição, pelos outros a mim e por mim aos outros, formará a base para os julgamentos sobre nossas condutas, que serão cruciais para o progresso ou fracasso de nossa cooperação-, no caso dos bens de excelência, serão tais que cada um de nós terá tido de aprender o que são e como julgar, considerando-as parte de sua educação para o tipo específico de atividade que visa aos bens particulares. [...]. Assim, as primeiras premissas de nosso raciocínio prático tratarão daqueles bens, premissas em cuja formulação progrediremos gradualmente à medida que melhor compreendermos o bem ou os bens que perseguimos; [...]. Além disso, a fim de raciocinar bem, teremos de ter aprendido como reconhecer sistematicamente o mérito onde ele for devido, isto é, termos de ter adquirido, no contexto do tipo específico de atividade, a virtude da Justiça, concebida em termos de merecimento. (MACINTYRE, 1991. p. 55).
\end{abstract}

A ação e o relacionamento fundados na justiça constituem outro patamar ou fase da justiça como um processo e possibilita a cooperação do indivíduo ao corpo social através de um artifício de promoção do bem e do melhor para a sociedade em que o ente se insere, a captação da relação/situação ocorrida antes do ato justo é essencial para o desenvolvimento e estudo da justiça como virtude do indivíduo e da sociedade que promove em seu mais alto estágio o bem da pólis, afinal de contas a justiça existe como mais alto parâmetro de excelência normativa. (PERINE, 1992, p. 392). 


\section{A busca pelo bem estar na Pólis}

O fato de se estabelecer parâmetros distintivos quanto à virtude possibilita arquitetar graduações ou níveis perante a qualidade do bem ou a busca pelo melhor ou mais qualificado. A ideia de múltiplos níveis de equidade ou a perspectiva de várias esferas de uma excelência é fundamental para a definição das variáveis.

A partir de critérios basilares em que determinados comportamentos doravante denominados de obrigações busca-se a concessão de práticas ditas devidas, ou seja, atitudes que se esperam do indivíduo ou de uma coletividade, práticas que devam ser permeadas pela consideração adequada ou justa medida, certa proporcionalidade que se espera de uma comunidade elencada como justa.

As concepções de mérito e de merecimento são destacadas também pelo exercício cotidiano, exercício esse denominado de decisão. A decisão nada mais é do que o ato racional resultante de um processo reflexivo que irá originar o ato justo ou injusto. Conceder ou não a alguém o que lhe é devido trata-se de uma decisão. Os critérios de merecimento são indispensáveis para a administração da justiça, de modo que as características, situações e condições de cada indivíduo aguçam uma atmosfera de atos justos. (DARR, 2020, p. 07)

A proposição de uma atmosfera de justiça e o estabelecimento de um âmbito de cooperação só se faz possível à medida que ocorra ampla interação entre os indivíduos. O jogo de perspectivas e expectativas para com o próximo é de suma importância e a relevância da questão é amplamente vislumbrada no tocante a interdependência dos indivíduos, possibilitando o bom relacionamento entre todos, o que de fato é essencial para o bom andamento de toda e qualquer comunidade que procura em si o desenvolvimento dos parâmetros de justiça. (LOOMIS; LOOMIS, 2020, p. 1).

A justiça é uma virtude por excelência, e exige a excelência dos que a procuram. $\mathrm{O}$ indivíduo que busca ser justo num plano inicial deve obrigatoriamente buscar a excelência de caráter. A igualdade e a reciprocidade de cooperação pretendem estabelecer a sintonia da comunidade justa e a harmonia entre todos os indivíduos. Sintonia e harmonia são concepções importantes no que tange ao estudo da justiça. A sintonia é para nós como o estado de comunhão em que todos os esquemas sociais e por consequência os cidadãos estão em consonância e seguem sua busca pelo bem mútuo. Já a harmonia é o exercício direto comum entre todos os indivíduos da pólis onde se desenvolvem os parâmetros de justiça.

Quando se refere a um exercício direto e comum fala-se de uma interação horizontal e de convívio e o aspecto comum seria o ordinário ou cotidiano, esses conceitos nos permitem 
que se entenda como funciona o arranjo de igualdade e os padrões de referência no plano da reciprocidade. Essa espécie de acordo mútuo deve iniciar, principalmente, por aqueles que se dizem detentores da justiça, ou seja, aqueles que detêm o poder administrativo e governamental de fazer valer as normas ou padrões de justiça.

Imputar o conhecimento devido referente à benemerência e honorabilidade dos preceitos de justiça aos depositários da equidade trata-se de uma tarefa primordial e indispensável, de cunho medular e vital para o aprimoramento da integridade e retidão no contexto social.

A ideia de que os parâmetros de justiça devem ser implantados inicialmente no contexto do órgão de execução torna necessário que os primeiros a se comprometerem com essa asserção sejam o conjunto estatal e os que lhe representam.

A proposta de uma justiça entre todos requer a inserção de uma política educacional de justiça, não apenas ou exclusivamente a institucionalizada, como nas escolas, mas sim aquela em que há a exposição de mandamentos e catequização dos indivíduos para a busca pelo benefício comum e bem da pólis. Por mais que existam concepções, bifurcações e inúmeras distinções teóricas quanto aos conceitos de justiça certo é que figura não somente como paradigma do social ou sociológico mas precipuamente como valor e virtude individual.

O caráter singular da justiça e sua aptidão para o particular e o pessoal fazem dela um dom do indivíduo ou ainda um predicado do ser. Quando se compreende no que se traduz essa dádiva, ao transcender o ego e ainda perpassar o plano da personalidade e da individualidade chegando por fim ao corpo social, é destampado a nós o encadeamento da justiça e a perspectiva de como se constrói a equidade a partir de si mesmo para o tratamento com todos. (BYRNE, 2020, p. 76.)

Os ensinamentos acerca desse critério de equidade ao se instituírem numa contingência de interação social sem detença demandarão a feitura de meios de efetivação e acatamento dos fatores de justiça. As normas, desta feita, imbuídas de critérios e conteúdos de justiça, ao requererem sua observação nada mais farão do que viabilizar o cumprimento de padrões que ao serem obedecidos denotam a absorção dos conceitos de justiça.

Desta forma, os conceitos sorvidos pelo cidadão virtuoso nada mais farão do que facilitar o acatamento de normas justas. Até este ponto o cumprimento e a subordinação aos padrões estabelecidos facilitam a vida e o convívio na pólis. O processo interno já foi de certa forma aqui exposto e procuramos esclarecer que depende do processo cognitivo de cada indivíduo, bem como, de sua predisposição ao bem ou a não pendência ao justo. A catequização 
desempenha um papel substancial e é nela que nos estribamos para estabelecer os parâmetros apresentados.

Outrossim, a explanação acerca das motivações para o ato justo já foram esclarecidas e servem de indicador para o autocontrole de cada cidadão, considerando suas boas razões para cada ação no plano das motivações. A partir dessa ideia de boas razões para a ação tem-se que há necessidade do exercício do raciocínio prático como forma de deliberação quanto ao bem a ser alcançado.

A atividade deliberativa será desenvolvida com base nas condições de meio e caráter, os parâmetros de influência serão considerados pelo indivíduo que deverá seguir qual o melhor comportamento para cada situação que se lhe apresentará. A partir de premissas constituídas anteriormente através de um processo de formação do sujeito é desenvolvido o processo de julgamento de ações.

O processo de sopesamento de valores e ações seguido pela consideração das atitudes a serem tomadas eleva o ente ponderador ao patamar racional de juiz interno ou de juiz das próprias ações. Torna-se, portanto o avaliador prévio de todas as decisões a serem tomadas. Esse processo é fundamental para a constituição dos anteriormente denominados ambientes de justiça, passando a ser denominado princípio de justiça, quando do inicio de sua existência como paradigma interno do ser.

Desse modo, assevera MacIntyre que:

A questão do que constitui uma boa razão para a ação é jogada sobre eles apenas quando já enfrentam alternativas, e, caracteristicamente, os primeiros usos do raciocínio prático servirão para justificar a busca de algum bem que não possa ser alcançado através das rotinas costumeiras do dia, do mês e do ano normais. (MACINTYRE, 1991. p. 66).

O desenvolvimento de uma prática argumentativa e manipuladora dos sentimentos e emoções do indivíduo permite que seja levado cativo todo e qualquer instinto hostil e de animosidade.

Isto se deve graças ao processo dialético e racional viabilizado por certo tribunal da consciência que permite a todo cidadão acusar-se ou defender-se de todo e qualquer pensamento que lhe vier em mente, oportunizando assim o diálogo interior e um exercício iniciado no estágio analítico de pensamentos e emoções.

A perspectiva de que "a justiça consiste em fazer o bem aos seus amigos e mal aos inimigos" de fato precisa ser analisada com mais assepsia, despojando-se dos preconceitos e 
desdéns teóricos quanto às ideias de retribuição. $\mathrm{O}$ mal ora proposto não se trata de maldade propriamente dita, mas sim de um pagamento ou punição ao erro praticado.

A preservação do bem-estar no círculo social e a manutenção da paz na pólis somente serão concretizados quando cada cidadão, em perfeito engajamento, desenvolver cada um a sua habilidade e predisposição ao bem, de forma que a participação de cada indivíduo na sua singularidade diz respeito principalmente à expectativa de contribuição para com o bem-estar social.

\section{Considerações finais}

A ideia de justiça é um tema muito discutido na atualidade e a maximização das mais variadas desigualdades emergem qual rio em seu nascedouro, desse modo, faz-se necessário não somente analisar mas entender as perspectivas de justiça de um ponto de vista prático e racional. A modernidade traz consigo inúmeros focos de discrepância e de desnivelamento social, de modo que enseja cada vez mais uma interpretação mais efetiva da assimetria sociológica existente. Analisar a justiça e o agir justo como um exercício é fundamental para a concretização da equidade como conceito aplicável e exequível.

O presente trabalho ao apresentar a dimensão da justiça como virtude na obra de Alasdair MacIntyre, analisando a ideia de racionalidade por ele exposta, articulando a perspectiva de raciocínio prático, juízo e ação avaliativa no exercício da virtude do justo definiu os principais conceitos evidenciados no texto do autor sobre o que é justiça, virtude, raciocínio e racionalidade, como meio de proporcionar uma melhor compreensão do que vem a ser a justiça como processo e atividade que leva à gênese de um comportamento humano adequado.

Levou-se em consideração os aportes hermenêuticos como forma de se chegar a uma resposta ao problema de aplicação da equidade como meio de materialização da justiça no mundo prático, interpretando-se os conceitos e teorias apresentados pelo autor e desenvolvendo a proposta por ele apresentada de uma racionalidade prática.

Os principais resultados obtidos em nossa investigação nos levam a acreditar que a aplicação da razão à conduta nos permite entender como a vontade pode ser racionalmente dirigida para uma atividade ou exercício justo, conduzindo o indivíduo para uma conduta reta e afastando-o das paixões. Mas o que é a paixão para MacIntyre? Bem, sob muitos aspectos ele se utiliza de vários autores para fundamentar suas ideias mas no tocante as paixões ele é categórico e nos dá a entender que trata-se de um apetite irascível ou ainda um vício oposto a uma virtude, assim, em suma, a racionalidade nos permite chegar em segurança ao agir justo. 
Quando MacIntyre nos esclarece o papel da racionalidade no agir humano ele não o faz em vão, na verdade procura preparar o caminho para expor sua ideia do agir justo e racional, racionalidade esta que afasta os vícios e permite uma conformação aos padrões corretos e justos aditados pelo autor.

Portanto, sob a ótica de MacIntyre, o padrão da justiça, como já vimos, é dado pela forma da justiça; e a ação justa, de acordo com esse padrão, é produzida por um amor justo cujo objeto é, na verdade a justiça divina. Essa perspectiva não se trata apenas de uma justiça divina de retribuição, maldições e demais consequências dos pecados da humanidade mas sim uma forma de preceitos e valores prescritos pela ordem divina como prescrição de virtudes aceitáveis. (MACINTYRE, 1991, p. 170).

Essa dimensão do amor aqui explanada e defendida por MacIntyre dá margem para uma interpretação mais extensiva, partindo-se da premissa que os agentes e destinatários da justiça estariam vinculados por uma relação de afeto ou amor, essa compreensão pode até mesmo, neste outro momento a partir de uma compreensão nossa, ser estendida a seres diferentes que não sejam os seres humanos.

Por fim, a compreensão da justiça emitida por Alasdair MacIntyre remete a necessidade de adesão por parte do indivíduo de uma dinâmica de agir fundada na racionalidade. A partir desta atitude as virtudes naturais poderão ser aperfeiçoadas e assim conduzir o indivíduo pela senda da justiça, nunca se esquecendo da lição de que a justiça é uma aplicação da razão à conduta e trata de como a vontade pode ser racionalmente dirigida para a conduta reta de forma que guiar-se pela razão prática é dirigir-se pelo caminho daquilo que é justo. (MACINTYRE, 1991. p. 216).

\section{Referências}

ÁLVAREZ, Ana Carolina Fascioli. ¿Es la vida familiar relevante para la justicia social? Ideas y Valores, Bogotá, n. 163, p. 81-103, abr. 2017. Disponível em:

http://dx.doi.org/10.15446/ideasyvalores.v66n163.49543. Acesso em: 14 mar. 2018.

BYRNE, Patrick H. Desiring and practical reasoning: Macintyre and Lonergan. International philosophical quarterly, v. 60, n. 1, p. 75-96, 2020.

BUTING, Jerome F. Illusion of Justice: Inside Making a Murderer and America's Broken System. New York: HarperCollins, 2017.

CAMPELO, Olívia Brandão Melo. A Ética e a Justiça para Alasdair Macintyre. Arquivo Jurídico, Teresina ,v. 1 , n. 6 , p. 1-21, jan./jun. 2014. 
CARDOSO, Flora Rocha. A Teoria Das Virtudes de Alasdair Macintyre. 2010. $143 \mathrm{f}$.

Dissertação (Mestrado em Filosofia) - Universidade Federal de Minas Gerais - UFMG, Belo Horizonte, 2010.

CARVALHO, Helder Buenos Aires de. Tradição e racionalidade na filosofia de Alasdair Macintyre. São Paulo: UNIMARCO, 1999.

CARVALHO, Helder Buenos Aires de. Hermenêutica e filosofia moral em Alasdair MacIntyre. 2004. 528f. Tese (Doutorado em Filosofia) - Universidade Federal de Minas Gerais - UFMG, Belo Horizonte, 2004.

CARVALHO, Helder Buenos Aires de. Comunidade moral e política na Ética das Virtudes de Alasdair MacIntyre. Ethic@, Florianópolis, v. 6, n. 4 p. 17-30, ago. 2007.

COITINHO, Denis. Rawls e a justificação da punição. Trans/Form/Ação, Marília, v. 40 n.3 Jul/Set. 2017. Disponível em: http://dx.doi.org/10.1590/s0101-31732017000300005. Acesso em: 14 mar. 2018.

DARR, Ryan. Virtues as qualities of character: Alasdair Macintyre and the situationist critique of virtue ethics. Journal of religious ethics, v. 48, n. 1, p. 7-25, 2020.

DOLOVICH, Sharon; NATAPOFF, Alexandra. The new criminal justice thinking. New York: New York University Press, 2017.

ERDI, Gülçin, ŞENTÜRK, Yildirim. (Eds.) Identity, justice and resistance in the neoliberal city. Basingstoke, England: Palgrave Macmillan, 2017.

FERREIRA NETO, Arthur Maria. Justiça como realização de capacidades humanas básicas: é viável uma teoria de justiça aristotélica-rawlsiana? Porto Alegre: EDIPUCRS, 2009.

GARGARELLA, Roberto. As teorias da justiça depois de Rawls: um breve manual de filosofia política. Tradução de Alonso Reis Freire. São Paulo: Martins Fontes, 2008.

GONÇALVES, João Pedro. O horizonte da Justiça em Alasdair MacIntyre. Braga: Universidade Católica Portuguesa, 2007.

LOOMIS, David; LOOMIS, Steven. Alasdair Macintyre's Challenge: Police Corruption, Management Ethics, And The Indispensable Virtues Of Integrity And Constancy.

International Journal Of Police Science \& Management, mar. 2020.

MACINTYRE, Alasdair. Three rival versions of moral enquiry. Encyclopaedia, genealogy, and tradition being Gifford Lectures delivered in the University of Edinburgh in 1988. Notre Dame: University of Notre Dame Press, 1990.

MACINTYRE, Alasdair. Justiça de quem? Qual racionalidade? Trad.: Marcelo Pimenta Marques. São Paulo: Loyola, 1991.

MACINTYRE, Alasdair. Depois da Virtude. Trad. Jussara Simões. Bauru, SP: EDUSC, 2001. 
MURPHY, Mark C. Alasdair MacIntyre: Contemporary Philosophy in Focus. Cambridge: Cambridge University Press, 2003.

PERINE, Marcelo. Virtude, justiça, racionalidade: a propósito de Alasdair Macintyre. Síntese Nova Fase, v. 19 n. 58, p. 391-412, 1992.

PERREAU-SAUSSINE, Emile. Alasdair MacIntyre - Une Biographie Intellectuelle. Paris: Presses Universitaires France, 2005.

WILLASCHEK, M. Which imperatives for Right? On the non-prescriptive character of juridical laws in Kant's Metaphysics of morals". In: TIMMONS, M. (ed.). Kant's metaphysics of morals, interpretative essays. Oxford: Oxford University Press, 2002. 